\title{
Gamification and mHealth technology: an approach to raise awareness and provide health education to the elderly
}

\author{
Levi M. Martins ${ }^{1}$, Renata J. G. Sousa ${ }^{1}$, Evaldinolia G. Moreira ${ }^{1}$, Dário V. Conceição ${ }^{2}$, \\ Jeane S. Ferreira ${ }^{1}$ \\ ${ }^{1}$ Instituto Federal do Maranhão - IFMA \\ Av. Getúlio Vargas, 4 - 65030-005 - São Luís - MA - Brasil \\ ${ }^{2}$ Ecole d'ingénieurs généraliste - EFREI \\ Paris, França. \\ \{levimmartins, renatajgsousa\}@gmail.com, dario.vieiraefrei.fr, \\ \{evaldinolia, jeane\}@ifma.edu.br
}

\begin{abstract}
According to the World Health Organization $31 \%$ of the deaths worldwide are caused by Cardiovascular Diseases (CVDs) and most are preventable by changing risk behaviors. It is known that aged people are more susceptible to have chronic diseases, and that the number of elderly is increasing. At the same time, the concern of public health systems on how to deal with this fact is emerging. The use of gamification is still not much explored when focused on aged people and represents a different approach to motivate and engage the target people in beneficial activities and teach them about a healthy lifestyle. In this paper we propose the use of an app with the adoption of gamification techniques, as a tool to provide medical literacy, prevention and behavioral changes.
\end{abstract}

\section{Introduction}

Population aging is a worldwide concern. It is estimated that by 2030 the population aged $\geq 65$ will increase from $6.9 \%$ to $12.0 \%$ all over the world. It is also predicted that the developing countries will be the ones with the greatest number of aged population [Control et al. 2003]. Aging is a strong risk factor for chronic diseases, such as cardiovascular diseases, cancer, type 2 diabetes, etc [Newgard and Sharpless 2013]. Therefore, the increase of the number of seniors will have a direct impact on health-care costs. The majority number of deaths worldwide are caused by the burden of Cardiovascular Diseases (CVDs), in 2012 was estimated 17.5 million of deaths caused by CVDs [WHO 2016]. Many studies have supported the positive impact of physical activity in the prevention of chronic diseases. Noncommunicable diseases (NCDs) such as: coronary heart disease, stroke, hypertension, type 2 diabetes, etc., have been correlated with sedentary lifestyle [Warburton et al. 2007]. In this context, we decided to develop a hybrid approach of gamification, the use of game design components in contexts not related to games [Deterding et al. 2011], and mHealth, new mobile communication and network technologies for healthcare systems [Istepanian et al. 2006], that is able to engage, and raise knowledge of healthy practices.

\section{Proposed Solution}

The project conceived as a way to raise awareness and provide medical literacy for prevention and behavioral changes is a Heart Rate Monitor (HRM) app. The app will be 
VI Congresso Brasileiro de Informática na Educação (CBIE 2017)

Anais do XXVIII Simpósio Brasileiro de Informática na Educação (SBIE 2017)

developed based on gamification techniques such as: points, badges, leader boards, levels, etc. In addition, there will be an easy interface to guide the user and show results and statistical graphs based on data stored during the use of the app, which can be shared with caregivers. The app is intended to be used by aged adults physically active and able to perform moderate exercises (physical function level IV) [Tribess 2016]. The Heart Rate Monitor is expected to be used before, during, and at the end of the exercises performed by the elderly. All the data will be stored and presented in the screen along with tips for healthy practices, points, badges or other gamification techniques to motivate and raise awareness, see Figure 1. The mainly purpose of this project is to aggregate educational aspects with the engagement of the elderly in healthy activities. Therefore, integrating non-game contexts into game contexts.

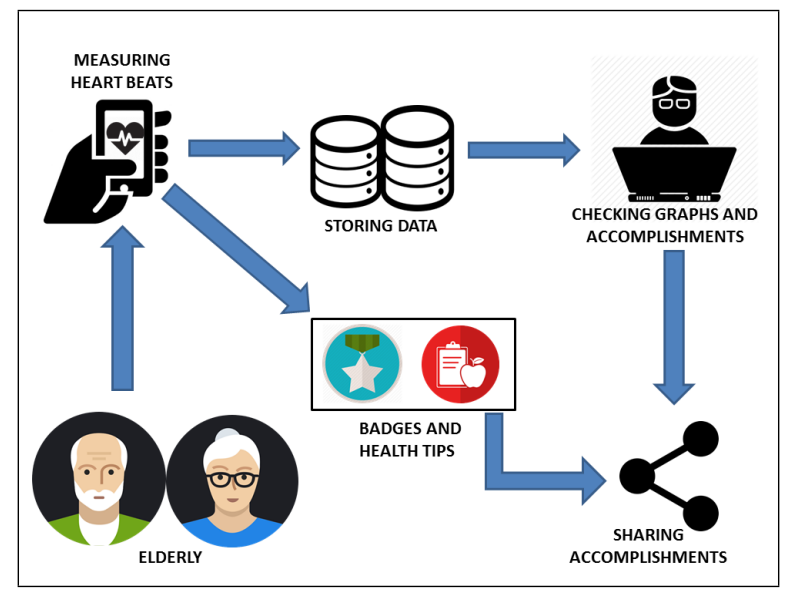

Figure 1. Model proposed

For the development of the app is being used the Android Studio environment. The sources codes are being implemented and adapted applying gamification techniques and data storage to the model. The sensor raw data are collected by the use of the Heart Rate Monitor(HRM) Sensor IR/RED Signal of the Samsung smartphone and accessed using the Sensor Extension granted by [SAMSUNG 2016], then these data need to be processed and transformed into heart beats per minute. In which concerns the web interface, it will be used responsive techniques to enable an easy access in smartphones, tablets, PCs, and other devices, the user will be able to share their results in different applications platforms such as facebook, whatsapp, etc.

\section{Final Considerations}

The idea of this research project is to use technology to educate and help fighting against the burden of Cardiovascular diseases, as well as to assist in the change of risk behaviors enabling people of all socioeconomic status to acquire a different approach of awareness. In addition, this project will contribute to the studies of mHealth and gamification focused on the elderly. Analysis on how to build proper and better models for the use of aged people remains a challenge to be studied further.

\section{References}

Control, C. F. D., Prevention, et al. (2003). Public health and aging: trends in aging - united states and worldwide. JAMA, 289(11):1371-3. 
VI Congresso Brasileiro de Informática na Educação (CBIE 2017)

Anais do XXVIII Simpósio Brasileiro de Informática na Educação (SBIE 2017)

Deterding, S., Dixon, D., Khaled, R., and Nacke, L. (2011). From game design elements to gamefulness: defining gamification. In Proceedings of the 15th international academic MindTrek conference: Envisioning future media environments, pages 9-15. ACM.

Istepanian, R., Laxminarayan, S., and Pattichis, C. S. (2006). M-health. Springer.

Newgard, C. B. and Sharpless, N. E. (2013). Coming of age: molecular drivers of aging and therapeutic opportunities. The Journal of clinical investigation, 123(3):946-950.

SAMSUNG (2016). Sensor extension. http://developer.samsung.com/ galaxy/sensor-extension. Accessed: 2017-05-27.

Tribess, S. (2016). Prescrição de exercícios físicos para idosos. Saúde. com, 1(2).

Warburton, D. E., Katzmarzyk, P. T., Rhodes, R. E., and Shephard, R. J. (2007). Evidenceinformed physical activity guidelines for canadian adults. Applied physiology, nutrition, and metabolism, 32(S2E):S16-S68.

WHO (2016). Cardiovascular diseases (cvds). http://www.who.int/ mediacentre/factsheets/fs317/en/. Accessed: 2016-11-12. 